\title{
Polygraphies du corps dans le roman de femme contemporain, numéro préparé par Andrea Oberhuber
}

\section{Eva Feole}

\section{(2) OpenEdition}

\section{Journals}

\section{Edizione digitale}

URL: http://journals.openedition.org/studifrancesi/624

DOI: $10.4000 /$ studifrancesi.624

ISSN: 2421-5856

\section{Editore}

Rosenberg \& Sellier

\section{Edizione cartacea}

Data di pubblicazione: 1 aprile 2015

Paginazione: 196-197

ISSN: 0039-2944

\section{Notizia bibliografica digitale}

Eva Feole, «Polygraphies du corps dans le roman de femme contemporain, numéro préparé par Andrea Oberhuber ", Studi Francesi [Online], 175 (LIX | I) | 2015, online dal 01 avril 2015, consultato il 18 septembre 2020. URL : http://journals.openedition.org/studifrancesi/624 ; DOI : https://doi.org/ 10.4000/studifrancesi.624

Questo documento è stato generato automaticamente il 18 settembre 2020.

\section{cc) (†) $\odot$}

Studi Francesi è distribuita con Licenza Creative Commons Attribuzione - Non commerciale - Non opere derivate 4.0 Internazionale. 


\title{
Polygraphies du corps dans le roman de femme contemporain, numéro préparé par Andrea Oberhuber
}

\author{
Eva Feole
}

\section{NOTIZIA}

Polygraphies du corps dans le roman de femme contemporain, numéro préparé par Andrea OBERHUBER, «Tangence» n. 103, 2013, pp. 145.

1 Costituito da sette articoli di studiose provenienti da Québec, Francia e Belgio e coordinato da A. Oberhuber, il dossier ruota intorno a quelle che il titolo stesso definisce, con le parole di Roland Barthes, «polygraphies du corps». Il volume si propone infatti di studiare in che modo e per mezzo di quali strategie narrative, alcune scrittrici e artiste di sesso femminile abbiano affrontato il tema del corpo e il suo complesso intreccio con questioni politiche e poetiche.

2 Proprio di Andrea OBERHUBER è il primo intervento, intitolato Dans le corps du texte (pp. 5-19), che funge da breve introduzione all'intero volume. Oberhuber articola il suo discorso intorno ai tre momenti - scrivere, descrivere e inscrivere - che fanno da cardine agli articoli che compongono il dossier. Il corpo, in particolare quello della donna, non si delinea qui come semplice elemento descrittivo: al contrario, diventa un'occasione per elaborare rivendicazioni sociali e disfare i nodi del proprio passato. Oberhuber ci ricorda così che il corpo non è uno, ma è plurale, al contempo individuale e sociale.

Infatti, con En-corps, brèves observations sur le manifeste d'Hélène Cixous (pp. 21-30), Martine REID dimostra proprio come il celebre Le Rire de la Méduse sia quasi un manifesto del corpo della donna, una rivendicazione di carne e materia, di sensazione e corpo. Corpo che, in questo caso, si fa scrittura e che proprio attraverso la scrittura trova un modo per liberarsi ed esprimersi. 
4 Altrettante implicazioni politiche della narrazione del corpo della donna sono affrontate nell'articolo di Sofiane LAGHouATI Les Je(ux) de partitions d'Assia Djebar: un Quatuor algérien pour corps féminins (pp. 31-56). Laghouati studia il carattere radicalmente originale dell'autobiografia nell'opera di Assia Djebar, con una particolare attenzione al modo in cui il corpo della donna diventa, nei suoi scritti, uno spazio simbolico di clandestinità.

5 Se Catherine MAVRIKAKIS (Le Corps de la filiation: répétitions et détournements de l'Histoire des femmes dans le roman "Purge" de Sofi Oksanen, pp. 57-78) affronta il tema della violenza subita dalle donne, nel romanzo finlandese Purge di Sofi Oksanen, Martine DELVAuX compie invece un'analisi intrecciata dei romanzi di Nelly Arcan e delle fotografie di Vanessa Beecroft (Écriture et nudité. Les femmes de Nelly Arcan et de Vanessa Beecroft, pp. 79-91). Delvaux pone le opere delle due artiste in un paragone dal quale risulta la medesima intenzione di non esaltare la nudità del corpo femminile, bensì di evocarne la caduta. Lo sforzo allora è forse per entrambe quello di liberarsi dall'immagine fin troppo consumata della donna, proprio per mezzo della sua narrazione.

In Le Corps dans la voix. De "L'Amour" à “L'Homme assis dans le couloir" de Marguerite Duras (pp. 93-105), Florence DE CHALOGNE, a partire dai manoscritti preparatori di L'Amour fino alla pubblicazione di L'Homme assis dans le couloir, e passando per le opere cinematografiche, analizza le strategie di cui la celebre autrice fa uso per dare vita ai suoi personaggi, in particolare attraverso lo stratagemma di una voce narrante che de Chalogne definisce - con un'espressione barthesiana - un «corpo nella voce».

7 Il volume si conclude con l'articolo di Marie-Dominique GARNIER Corps calliens: suite deleuzienne (nom, corps, nomos) (pp. 107-134), incentrato sull'opera della fotografa e scrittrice Sophie Calle. Rifacendosi al pensiero di Deleuze e Guattari, Garnier prende in esame alcune opere dell'artista parigina per analizzare come queste riescano a narrare un corpo i cui contorni non esauriscono mai i concetti di soggetto, individuo e identità, facendo così variare il perimetro di ciò che siamo abituati a considerare come un corpo.

Il dossier nel suo complesso rispecchia la vocazione volutamente interdisciplinare della rivista «Tangence», la cui peculiarità risiede proprio nell'interesse rivolto alle relazioni esistenti tra la letteratura e altre discipline. Nutrito quindi da contributi aperti a diversi approcci di analisi e alla contaminazione con espressioni artistiche anche lontane da quella letteraria, questo numero ha il pregio di donare al lettore una stimolante varietà di spunti di riflessione circa la questione - oggi ancora molto attuale e dibattuta - del corpo della donna. 